\title{
Novel Technique for Removal of the Uterus after Laparoscopic Hysterectomy
}

\author{
Sumathi Kotikela ${ }^{1}$, Michael L. Lewis ${ }^{1}$, Arathi Veeraswamy ${ }^{1}$, Camran Nezhat ${ }^{1}$ \\ 1. Center For Special Minimally Invasive Surgery, Stanford University School of Medicine \\ $\square$ Corresponding author: Sumathi Kotikela, sumathi_richard@hotmail.com \\ Disclosures can be found in Additional Information at the end of the article
}

\section{Abstract}

Novel technique for removal of large myomatous uteri following laparoscopic hysterectomy using Alexis wound retractor system. This technique demonstrates how to remove a large uterus vaginally following laparoscopic hysterectomy with relative ease.

Categories: Obstetrics/Gynecology, General Surgery

Keywords: laparoscopic hysterectomy, vaginal exposure, vaginal hysterectomy, vaginal retractor, laparoscopic myomectomy, laparoscopic assisted myomectomy

\section{Introduction}

Uterine leiomyomas are one of the most common benign smooth muscle tumors in reproductive age women. Despite the introduction of minimally invasive techniques, majority of myomectomies and hysterectomies are performed by laparotomies. It is important that the surgeon be knowledgeable about innovations and techniques related with laparoscopy. In our case, we present the use of ring retractor (Alexis) for delivery of the large uteri (Figure 1). 


\section{Cureus}

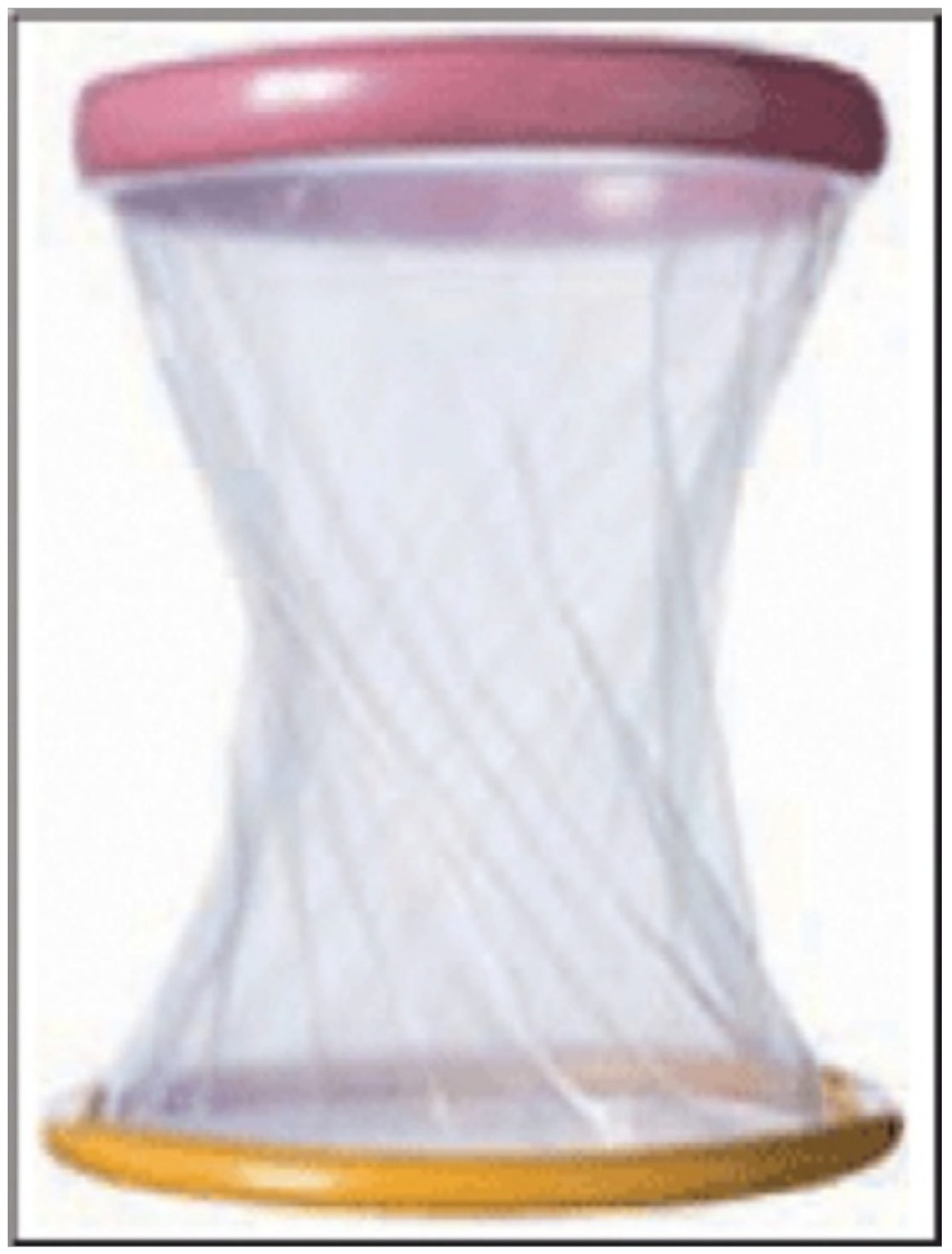

FIGURE 1: Ring Retractor 


\section{Cureus}

\section{Technical Report}

Following laparoscopic hysterectomy or laparoscopic myomectomy [1], we used the Ring retractor (Alexis), which is a disposable self-retaining retractor commonly used in abdominal surgeries [2]. This Ring retractor is placed through the vagina under direct visualization of laparoscope and secured into position with one semi-flexible ring on the peritoneal side and the other on the perineal side (Figure 2). Now the myomatous uterie is directed to the vaginal cuff with a grasper with teeth. Then, a double tooth tenaculum is used to hold the specimen and deliver it through vagina (Figure 3). Even a 16 to 20 week size uterus is delivered with relative ease. A weighted speculum is placed on the posterior wall of vagina over the ring retractor to prevent damage to vagina while cutting the specimen.

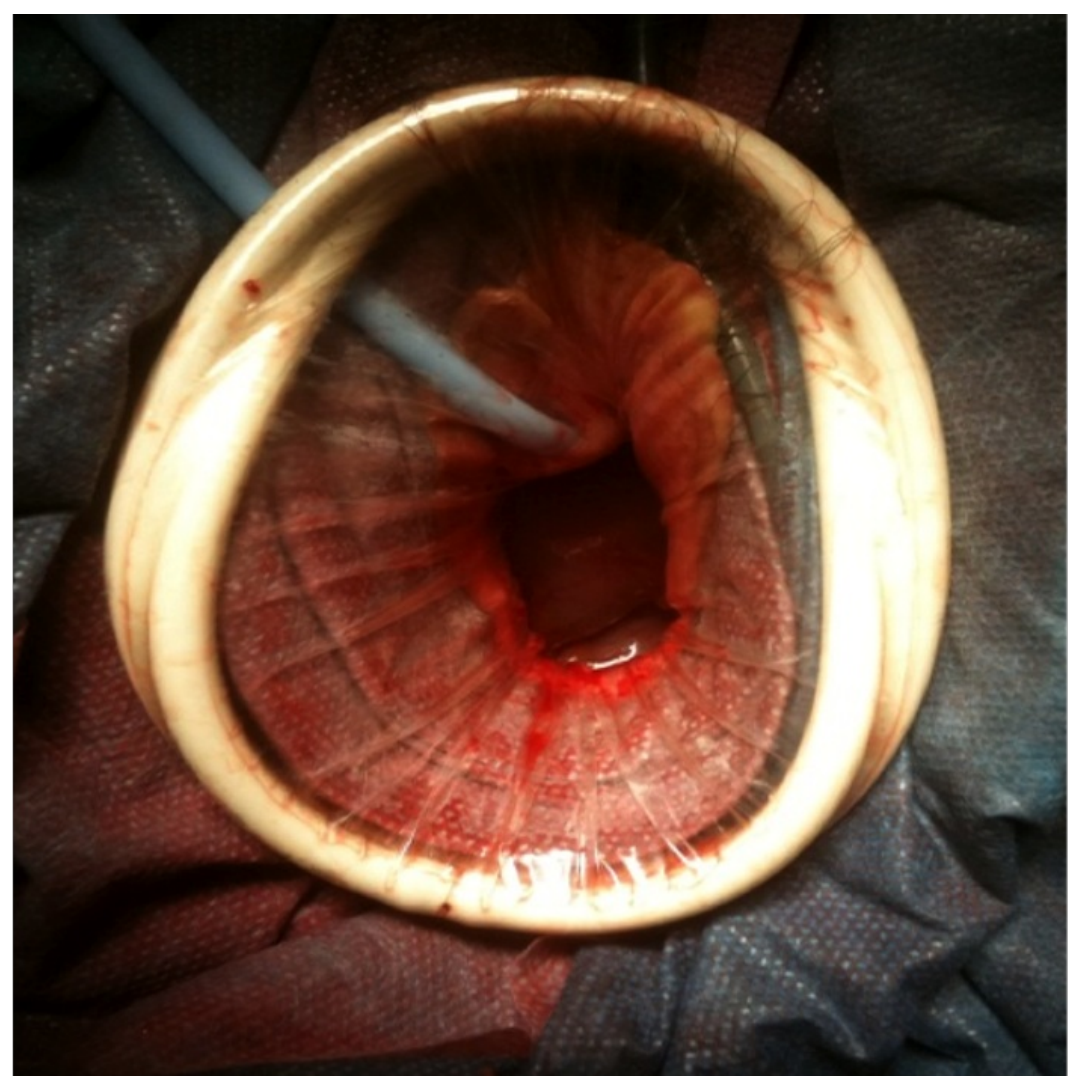

FIGURE 2: Application of Alexis in vagina 


\section{Cureus}

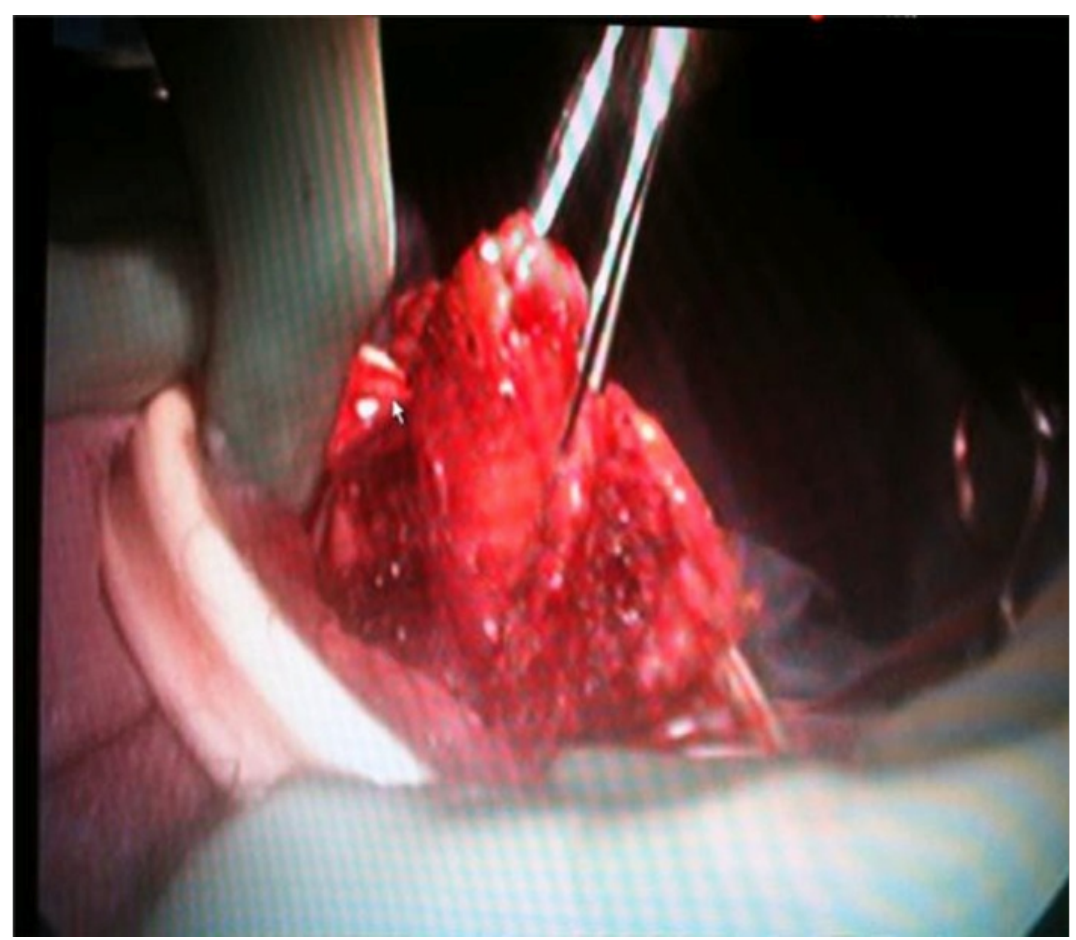

FIGURE 3: Removal of fibroid uterus

\section{Discussion}

In our case, use of the ring retractor is particularly helpful to avoid mini-laparotomies. Atraumatic circumferential retraction of the vagina helps with better visualization and removes the need for assistance during surgery [3]. Special care needs to be given when the inner ring is placed and any potential damage can be avoided when placed under laparoscopic guidance. In our institution, we have removed 16 to 20 week size fibroid uterus by Alexis retractor in nulliparous patients with relative ease.

\section{Conclusions}

Alexis Wound Retraction System initially designed for circumferential and atraumatic retraction during abdominal surgery is a viable alternative to standard retraction techniques when large uteri are removed vaginally.

\section{Additional Information}

\section{Disclosures}

Human subjects: All authors have confirmed that this study did not involve human participants or tissue. Animal subjects: All authors have confirmed that this study did not involve animal subjects or tissue. Conflicts of interest: In compliance with the ICMJE uniform disclosure form, all authors declare the following: Payment/services info: All authors have declared that no financial support was received from any organization for the submitted work. Financial relationships: All authors have declared that they have no financial relationships at present or within the previous three years with any organizations that might have an interest in the submitted work. Other relationships: All authors have declared that there are no other relationships or activities that could appear to have influenced the submitted work. 


\section{Cureus}

\section{References}

1. Nezhat C, Nezhat F, Nezhat C: Nezhats Operative Gynecologic Laparoscopy and Hysteroscopy. Cambridge University Press, New York, NY; 2008.

2. Magrina J: Self-retaining retractor for vaginal operations. J Gynecol Surg. 1991, 7(1):33-36.

3. Kho K, Shin J, Nezhat C: Vaginal extraction of large uteri with the Alexis retractor . J Minim Invasive Gynecol. 2009, 16:616-617. 10.1016/j.jmig.2009.06.013 